\title{
Non-Atherosclerotic Fusiform Aneurysms
}

Can. J. Neurol. Sci. 2002; 29: 5

Findlay and colleagues, ${ }^{1}$ in this issue of the Journal, draw attention to an interesting subgroup of aneurysms which have in common unique morphologic and histologic features but which vary in location and in the presence of important perforating arteries and therefore in therapeutic responsiveness. Fusiform aneurysms are enlarged segments in continuity with a main arterial trunk, often with relatively smooth tapered ends and with separate inflow and outflow openings. Perforating arteries may be incorporated into the enlarged segment, particularly in the basilar and proximal middle cerebral arteries. The histologic hallmark of this group of aneurysms is a circumferential absence of normal elastica and media without atherosclerosis. Such fusiform aneurysms may in some cases evolve into serpentine aneurysms that are giant lesions full of thrombus and traversed by a meandering residual arterial channel. Fusiform aneurysms may occur in association with tuberous sclerosis, Marfan's Syndrome, neurofibromatosis, and cutaneous vascular anomalies. They have been reported following craniopharyngioma removal, usually, but not invariably, when radiation therapy has been used following the surgery. Rarely, involved arterial walls of some fusiform aneurysms have been shown to have an inflammatory process present. A curious sub-group of fusiform aneurysms is that of the anterior cerebral artery associated with an adjacent lipoma of the corpus callosum. The fusiform aneurysms described above should be differentiated from the atherosclerotic aneurysms involving the vertebrobasilar circulation in elderly males, in which there is not only expansion of long arterial segments but also elongation [dolichoectasia]. ${ }^{2,3}$ In by far the largest surgical series, ${ }^{4}$ about half of the fusiform aneurysms presented with mass effect and about one-fifth with hemorrhage. Good outcome occurred in three-quarters of anterior lesions and none out of ten posterior ones. In a smaller but still large series, the fractions were reversed. ${ }^{5}$

Proximal ligation by clip or balloon is the simplest and frequently a very successful treatment. This is particularly true in younger patients with proximal internal carotid, posterior cerebral and vertebral aneurysms. It is much more problematic with proximal middle cerebral or basilar ones. The outcome depends on the ability of collateral circulatory beds to supply both the cortical and deep-perforating circulations rendered ischemic by proximal occlusion, trapping or clip reconstruction. I am skeptical about the general utility of wrapping, which is obviously impractical when long segments of arteries with the numerous perforators are involved. The good short-term outcome reported in Case 11 in Findlay's series probably reflect the natural history rather than the benefit of wrapping an incidental seven-millimeter fusiform aneurysm. I think that ECIC bypass is probably unnecessary in the great majority of children and teenagers subjected to carotid ligation. ${ }^{6}$ It would be interesting to know whether remodeling of the communicating arteries, leptomeningeal collateral circulation development or the bypass were responsible for the good outcome in Case 2.

Recently, there has been some hope that internal stenting and extra-stent intra-aneurysmal coiling could be used effectively in some fusiform aneurysms previously considered refractory to treatment, such as the one causing death in this series, which followed a surgical clipping. ${ }^{7,8,9,10}$

Bryce Weir

Chicago, Illinois

\section{REFERENCES}

1. Findlay JM, Hao C, Emery D. Non-atherosclerotic fusiform cerebral aneurysms. Can J Neurol Sci 2002;29:41-48.

2. Weir B. Aneurysms Affecting the Nervous System. William \& Wilkins. 1987;134-139.

3. Weir B. Subarachnoid Hemorrhage: Causes and Cures. Oxford University Press. 1998;124; 210-211.

4. Drake CG, Peerless, SJ. Giant fusiform intracranial aneurysms: review of 120 patients treated surgically from 1965 to 1992 . J Neurosurg 1997; 87:141-162.

5. Anson JA, Lawton MT, Spetzler RF. Characteristics and surgical treatment of dolichoectatic and fusiform aneurysms. J Neurosurgery 1996;84:185-93.

6. al-Yamany M, Ross IB. Giant fusiform aneurysm of the middle cerebral artery: successful Hunterian ligation without distal bypass. Br J Neurosurgery 1998;12:572-575.

7. Brassel F, Rademaker J, Haupt C, Becker H. Intravascular stent placement for a fusiform aneurysm of the posterior cerebral artery: case report. Eur Radiol 2001;11:1250-1253.

8. Higashida RT, Smith W, Gress D, Urwin R, Dowd CF, Balousek PA, Halbach VV. Intravascular stent and endovascular coil placement for a ruptured fusiform aneurysm of the basilar artery. Case report and review of the literature. J Neurosurg 1997;87:944-949.

9. Lylyk P, Cohen JE, Ceratto R, Ferrario A, Miranda C. Combined endovascular treatment of dissecting vertebral artery aneurysms by using stents and coils. J Neurosurg 2001;94:427-432.

10. Morizane A, Sakai N, Nagata I, Nakahara I, Sakai H, Kikuchi H. Combined endovascular stent implantation and coil embolization for the treatment of a vertebro-basilar fusiform aneurysm: technical case report. [Japanese]. No Shinkei Geka Neurological Surgery 2000;28:811-816. 